\title{
SHORT-TERM PREDICTION AND ANALYSIS OF WAVE-INDUCED MOTION AND LOAD RESPONSES OF A WAVE-PIERCING TRIMARAN
}

\author{
UDC 629.5.015.4:629.5.022.3 \\ Original scientific paper
}

\begin{abstract}
Summary
In this paper, we used a statistical short-term analysis in order to determine the waveinduced motions and loads responses of a trimaran ship with three side hull configurations including symmetric, inboard and outboard types. The calculation of these wave-induced loads was carried out using MAESTRO-Wave, a seakeeping analysis code. A rule-based design for the hull was created based on the American Bureau of Shipping (ABS) rules followed by building a global FEM model of the ship with MAESTRO to predict the waveinduced motion and load responses. In order to validate the numerical prediction, we tested a rigid segmented model of trimaran with symmetric side hull configuration in the National Iranian Marine Laboratory (NIMALA) towing tank. The numerical results revealed that transverse torsion moments and shear forces are significant in head seas. But, transverse bending moments have higher response magnitudes in oblique seas. Also, in transverse wave loads, outboard side hulls offer slightly better performance in waves in comparison to the other forms. This study offers useful information on wave-induced motion and load responses for the purpose of balancing sea-keeping performance as well as other design considerations in developing the conceptual design of a wave-piercing trimaran.
\end{abstract}

Key words: $\quad$ Trimaran; short-term prediction; cross structure; wave-induced motion and load 


\section{List of symbols}

$\begin{array}{llll}\text { Symbol } & \text { Definition } & \text { Symbol } & \text { Definition } \\ A_{j k} & \text { Matrix of added mass } & U & \text { Vessel speed } \\ B_{j k} & \text { Matrix of damping coefficient } & X_{j} & \text { Exciting forces and moments } \\ C_{j k} & \text { Matrix of restoring forces and } & \eta_{k} & \text { Body motions } \\ & \text { Moments coefficient } & & \\ D(\omega, \theta) & \text { Spreading function } & \omega_{e} & \text { Wave encounter frequency } \\ H & \text { Response amplitude operator } & \omega_{p} & \text { Peak frequency } \\ H_{s} & \text { Significant wave height } & \phi_{D} & \text { Diffraction potential } \\ m_{0} & \text { The zero-th moment } & \phi_{I} & \text { Incident wave potential } \\ M_{j} & \text { Wave-induced bending moment } & \phi_{i} & \text { Radiation potential } \\ M_{j k} & \text { Mass matrix } & \Phi(\mathrm{x}, \mathrm{y}, \mathrm{z}) & \text { Total velocity potential } \\ Q_{j} & \text { Wave-induced shear force } & \beta & \text { Relative wave heading } \\ S_{\zeta}(\omega) & \text { Wave spectrum } & \gamma & \text { Incident wave heading } \\ S_{R} & \text { Ship response spectrum } & \theta & \text { Wave spreading } \\ S_{\zeta}(\omega, \theta) & \text { Wave spectral density } & \varphi(\mathrm{x}, \mathrm{y}, \mathrm{z}) & \text { Disturbance potential } \\ T_{p} & \text { Peak period } & \omega & \text { Incident wave frequency } \\ T_{z} & \text { Average zero-crossing period } & \zeta_{a} & \text { Wave amplitude }\end{array}$

\section{Introduction}

Trimaran is a developed hull vessel which includes three independent hulls. This exceptional hull structure is in essence a very slender type of the conventional mono-hull attached to two smaller side hulls which are referred to as floats or outriggers. These side hulls are important in increasing the hydrodynamic and operational function of the vessel, though they only carry below 10 percent of the total displacement and are less than one third of the main hull length. Greater stability, a larger deck area, stronger endurance, a better maneuverability and lower resistance to high speed make trimaran a right choice for naval architects, both for civilian and military purposes.

Generally speaking, wave-induced loads on the structure of a monohull ship include vertical shear force, vertical bending moment, longitudinal torsion moment, etc. As a result of trimaran's cross structure, it is also vulnerable to transverse wave loads including transverse shear force, transverse bending moment, and transverse torsion moment, which are created due to the hydrodynamic interaction between the main hull and the side hulls. As a result of this side hull configuration and its different placements, there is an important effect on wave motions and wave-induced structural loads. Many studies have examined different aspects of trimaran's hydrodynamic interactions, but little research is carried out on the issue of the wave-induced motions and loads of trimarans.

Brizzolara and Rizzuto [1] studied the load acting on trimaran ship using a simplified model according to a quasi-static wave method. They found that the utilized model was 
appropriate in choosing the right stagger and clearance positions of the side hulls. Boote et al. [2],[3] developed a procedure for assessing the long-term design loads of a fast ferry trimaran. They used a HSC code to establish the scantling weight of the structure and a sea-keeping panel code to analyses its long-term wave load. Fang et al. [4] examined the overall loads of a trimaran in oblique waves by using a 3D translating-pulsating source distribution model. The researchers predict the long-term and transverse wave load responses at a number of different angles and frequencies of the waves. Fang and Chen [5] used a combination of pulsating source potential model and a 3D panel method to drive the significant wave loads of a trimaran in positioning different longitudinal and transverse arrangements of side hulls. Min and Shi-lian [6] conducted a numerical study applying the 3D potential theory and Green's function in order to predict the short-term wave loads of a trimaran which contained outriggers of different lengths and layouts. Hashimoto et al. [7] studied the way that the hydrodynamic forces of a trimaran could be affected by different positions of the side hulls. They performed a number of comprehensive model experiments using several outrigger positions. They found that the backward position of the side hulls was effective in reducing the resistance and maneuverability of the ship.

Shehzad et al. [8] analyzed the overall strength of a trimaran ship. They categorized trimarans based on the FE method using the calculation procedure of Lloyd's Register rules. They were able to identify points of maximum stress concentration to improve the strength of the structure. Bashir et al. [9] conducted a number of model tests on a Deep-V catamaran to predict wave-induced loads and motions. Using a 3D-panel method code MAESTRO-Wave, they were able to compare the results with numerical predictions. The predicted and measured results correlated reasonably. Ma et al. [10] proposed a practical method for balancing the loads in FE model and hull girder sectional loads which were taken from hydrodynamic analysis. They utilized the MAESTRO-Wave in order to validate their method. MAESTROwave was also used by Prini et al. [11] to examine the sea-keeping performance of a search and rescue craft (lifeboat) in regular waves. A general finite element model of this rescued craft or lifeboat which combines hydrodynamic and structural analyses was developed using MAESTRO-Wave. The validity of the numerical model was verified through a broad comparison between the experimental model tests and the full-scale trials. Xiaobo et al. [12], by performing numerical computations using WACLS and WASIM software, performed a series of experiments on a segmented model of a trimaran in different sea conditions. The comparison made between measured results of zero speed and non-zero speed matched better with the numerical computation of zero speed. Kim et al. [13] studied the wave induced motion responses and structural loads at mid-ship section with hydrodynamic interaction effect between two offshore floating structures in various heading waves by using a linearized three-dimensional potential theory. Numerical calculations give a good correlation with the experimental results and also with other numerical results. Tang et al. [14] designed and developed Structural Monitoring and Assessment System (SMAS) for trimaran ship. The selfpropelled trimaran model is installed with sensors in different longitudinal positions to monitor the variety of structural responses in irregular waves. The influence of different wave azimuths and monitoring positions on structural strength assessment is analyzed. Jiang et al. [15] studied the wave induced motions of a trimaran sailing in regular head waves by using the three dimensional boundary integral method. A practical approach was employed to suppress the large wave elevation by laying a lid on the free surface in between hulls.

The main focus of current work was to develop a methodology for determination of wave loads experienced by cross deck of trimaran ship, through experimental and numerical techniques. In this research short-term prediction of wave-induced motions and loads on the cross deck of trimaran with three kinds of side hull configuration (symmetric, inboard and outboard types this vessel was performed. This study offers useful information on wave- 
induced motion and load responses for the purpose of balancing sea-keeping performance as well as other design considerations in developing the conceptual design of a wave-piercing trimaran.

\section{The physical and FEM model description}

The trimaran model assembled with rigid body segments including a main hull with quite slender wave piercing bow profile and two side hulls with Wigley hull forms. The rigid segmented model is conceptually designed to transmit all the experienced loads on the hull to the load measurement system without losing them in structural deformation. Segments and components are not subjected to any deformation, so that collection of wave-induced loads is possible at load cell devices. Generally, the load cell devices link between a foundation and each rigid body segment. An adjacent segment is not directly connected; they are connected through the foundation. The foundation is firmly fixed to a towing tank carriage for the wave excitation force test or is attached on an oscillatory device for the radiation force test. Therefore, the rigid segmented model does not consider hydroelastic effects in the waveinduced load measurements. The bow profile of the main hull is wave piercing to improve the hydrodynamic characteristic of the ship. The geometrical scale ratio between the mode and prototype is defined as 1:80. Main particulars of the full scale and model scale of trimaran are reported in Table 1. A transverse cross-bridge tube joining the side hulls to center hull was designed and fabricated. To install the load cell between the segments through the foundations, cross-bridge tube was split at the center of the cross deck. The trimaran model is shown in Figure 1.

Table 1 Main particulars of the prototype trimaran and its scaled model

\begin{tabular}{|l|c|c|}
\hline \multicolumn{1}{|c|}{ Particular [unit] } & $\begin{array}{c}\text { Full } \\
\text { scale }\end{array}$ & Model scale \\
\hline Length overall [m] & 124.38 & 1.555 \\
\hline Length on waterline [m] & 123.24 & 1.541 \\
\hline Length between perpendiculars [m] & 120.10 & 1.501 \\
\hline Beam overall [m] & 21.78 & 0.272 \\
\hline Beam on waterline [m] & 9.612 & 0.121 \\
\hline Depth [m] & 11.78 & 0.147 \\
\hline Draft [m] & 4.38 & 0.055 \\
\hline Length of side hull [m] & 36.00 & 0.450 \\
\hline Beam of the side hull [m] & 2.362 & 0.030 \\
\hline Depth of the side hull [m] & 8.136 & 0.102 \\
\hline Draft of the side hull [m] & 2.72 & 0.034 \\
\hline $\begin{array}{l}\text { Clearance between the centreline of the } \\
\text { main hull and the centreline of the side } \\
\text { hull [m] }\end{array}$ & 9.700 & 0.121 \\
\hline $\begin{array}{l}\text { Stagger between the mid-ship of the side } \\
\text { hull and the mid-ship of main hull [m] }\end{array}$ & 25.00 & 0.313 \\
\hline Displacement (ton) & 2249 & 0.0044 \\
\hline
\end{tabular}




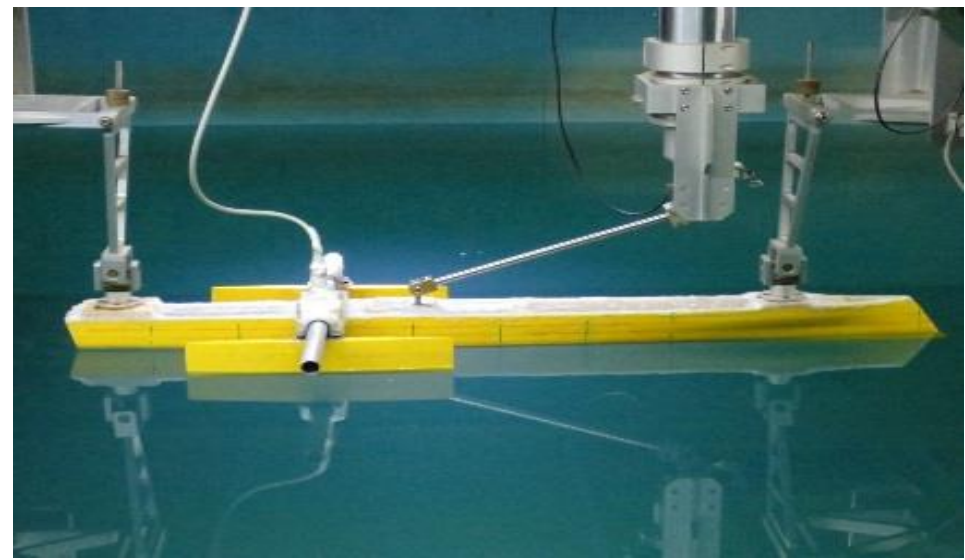

Fig. 1 The trimaran model installed in towing tank.

A simulation of the global FEM of a trimaran in the full load condition was created based on the ABS rules. The structural material of the model was made of marine steel grade of AH36 to get lower construction cost and fatigue. The main tanks and compartments were situated in both central and side hulls of the model. The main ship components and payloads (including deck house, basic machinery, generators, weapon systems with ammunition and helicopters) were modelled as weights distributed on a certain number of nodes. The structural configurations of the main hull, outriggers and cross decks include a long-term framing system with frame spaces of $1000 \mathrm{~mm}$. Particular considerations were given to the junctions of cross decks and the main hull in order to avoid the concentration of the stresses on the main hull. Based on the ABS rules, the minimum scantlings were defined for each member and the strength of the mid-ship part was checked against the global and local design loads. The FE model is shown in Figure 2.

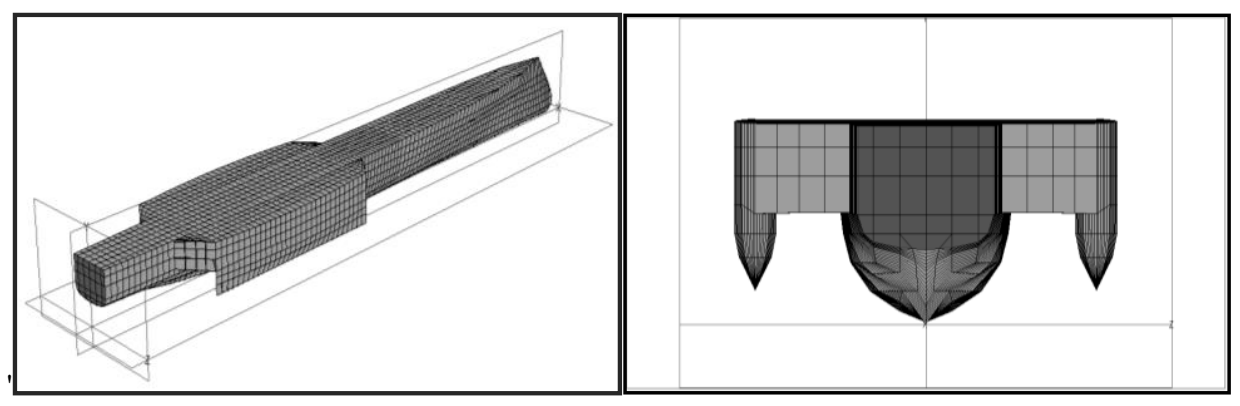

(a)

(b)

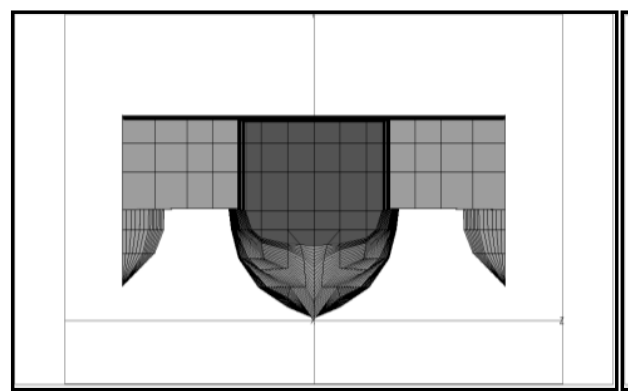

(c)

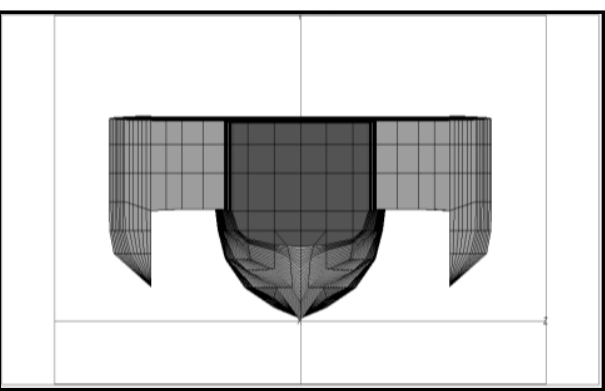

(d)

Fig. 2 a) Finite Element Model of trimaran and three kinds of side hull forms b) Symmetric c) Inboard and d) Outboard outriggers. 


\section{Numerical predictions}

At the present, the common method of calculating wave loads is strip theory. However, because of the significant interaction between the main hull and side hulls, the strip theory may not be suitable for analyzing trimarans, in which the interaction between strips along the ship length is not considered. Also it is too complicated to analyze the interaction among three hulls in strip theory [6]. In this article, a 3D panel linear code called MAESTRO-Wave was used to predict the wave loads of this vessel [16]. The code has been developed according to the potential flow theory. It uses the Green's function integral equation's technique to determine the unsteady potentials in order to solve the boundary value problem of interaction between water waves and bodies in the frequency domain. The hydrodynamic pressures and forces on the body surface imposed by wave conditions are calculated by the Bernoulli's equation. MAESTRO software is a powerful commercial program used in ship design, analysis and evaluation. Today, MAESTRO is used by navy forces, designers and universities. The code is used for predicting motions and wave-induced load responses of marine vessels and installations used in deep and shallow water conditions including catamarans and trimarans. The main reason for using this software was that it does not necessitate using Finite Element (FE) mesh apart from the hydrodynamic mesh while conducting structural analysis of the same hull geometry. As a result, this process guarantees that there is a balance between the hydrodynamic and the FE meshes; therefore it reduces the problem of convergence between the two different meshes, which mostly happens while the hydrodynamic mesh is imported into an FE program.

\subsection{The theoretical method for wave loads}

A trimaran ship moving in six degrees of freedom at a steady mean forward speed among the regular waves with small amplitudes in a right-handed Cartesian coordinate system $\mathrm{O}$-xyz is considered (see Figure 3). In order to predict the wave induced loads and motions of the ship, the equation of coupled linear motions is written as follows [18]:

$$
\sum_{k=1}^{6}\left[-\omega_{e}^{2}\left(M_{j k}+A_{j k}\right)+i \omega_{e} B_{j k}+C_{j k}\right] \eta_{k}=X_{j} \quad, \mathrm{k}=1,2, \ldots, 6
$$

where $A_{j k}$ and $B_{j k}$ are the added mass and damping coefficient which originate from the radiation potential. $X_{j}$ is the exciting force due to the incident and diffracted wave potential.

The RAO (response amplitude operator) can be obtained by solving the linear equation of motion. In order to solve this equation the values of mass matrix, added mass, damping coefficient, the restoring coefficient and exciting force and moment have to be calculated first. Imagine that a trimaran ship advances at a steady speed $U$ while the amplitudes of its motions and incidental waves are small and the fluid is totally homogeneous and incompressible. The total velocity potential $\Phi(x, y, z)$ in the fluid domain can be expressed as:

$$
\Phi(x, y, z)_{\text {Total }}=[-U x+\varphi(x, y, z)]_{\text {Double Body }}+\left[\left(\phi_{I}+\phi_{D}+\sum_{j=1}^{6} \eta_{j} \phi_{j}\right) e^{i \omega_{e} t}\right]_{\text {unsteady }}
$$

where the incident wave potential in this equation is known for a sinusoidal wave and is defined as follows:

$$
\phi_{I}=i \frac{g \alpha}{\omega} e^{-i k(x \cos \beta-y \sin \beta)} e^{k z}
$$


where $\alpha$ is the wave amplitude, $k$ is the wave number, $\beta$ is the wave heading angle ( $\beta=0$ for following wave) and $\omega$ is the wave frequency.

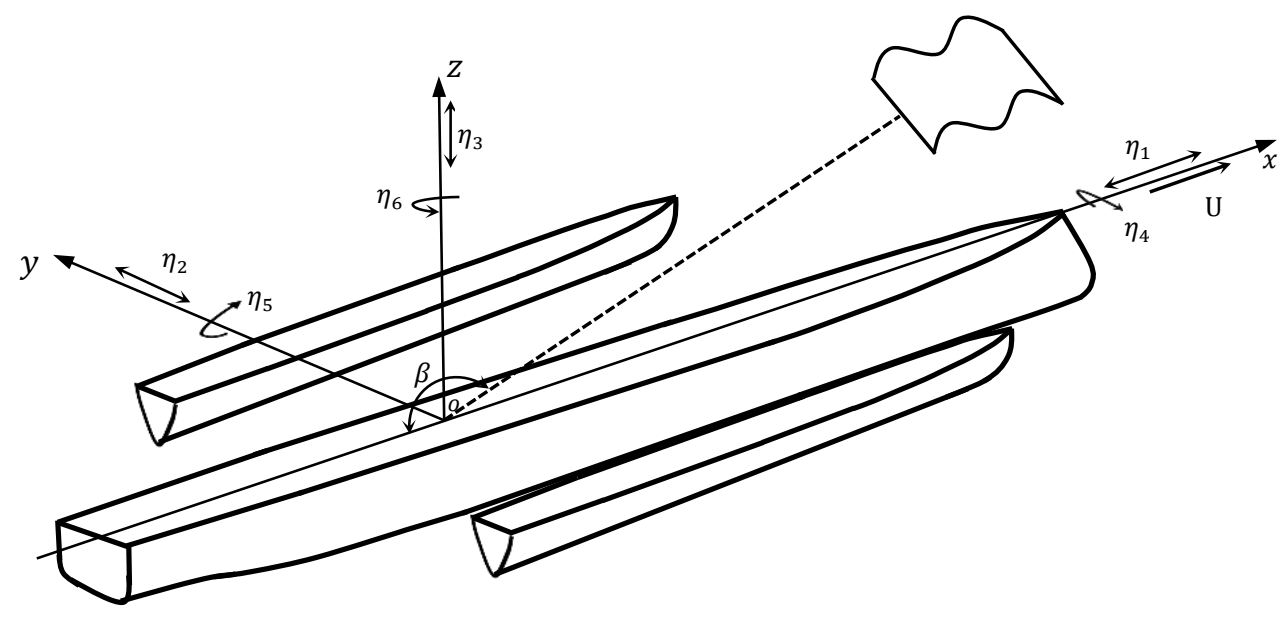

Fig. 3 Coordinate system of the trimaran ship.

In order to obtain the velocity potentials, the free surface and the boundary condition must be linearized to satisfy the assumptions of a linear potential theory. Integration of the pressure over the hull surface yields the hydrodynamic force and moment amplitudes. After obtaining the velocity potentials, the pressure of the body surface as a result of the given wave conditions can be calculated from the Bernoulli's equation which is expressed as [18]:

$$
p=-\rho\left(\frac{\partial \Phi}{\partial t}+\frac{1}{2}|\nabla \Phi|^{2}+g z\right)
$$

For short crested waves the term $\nabla \Phi . \nabla \Phi=\nabla \Phi^{2}$ is second order and much smaller than the first order terms of Eq.4.

The forces and moments, including wave induced pressure loads over the wetted surface (B) and inertial loads on the body are:

$$
F_{j}=\iint_{B} p n_{j} d s-\omega_{e}^{2} \sum_{j=1}^{6} M_{j k} \eta_{k} \quad j=1, \ldots, 6
$$

where $F=\left(F_{1}, F_{2}, F_{3}\right)$ are the force components in the $\mathrm{x}, \mathrm{y}$ and $\mathrm{z}$ directions, while $M=\left(F_{4}, F_{5}, F_{6}\right)$ are the moments about the $\mathrm{x}, \mathrm{y}$ and $\mathrm{z}$ axes. $\mathrm{M}_{\mathrm{jk}}$ is the mass matrix. Newman (1977) gives a general expression for the mass matrix, as follows [19]:

$$
[\mathrm{M}]=\left[\begin{array}{llllll}
\mathrm{M} & & & & & \\
& \mathrm{M} & & & & \\
& & \mathrm{M} & & & \\
& & & \mathrm{I}_{11} & \mathrm{I}_{12} & \mathrm{I}_{13} \\
& & & \mathrm{I}_{21} & \mathrm{I}_{22} & \mathrm{I}_{23} \\
& & & \mathrm{I}_{31} & \mathrm{I}_{32} & \mathrm{I}_{33}
\end{array}\right]
$$


The ship hull girder cross section shear forces and bending moments are:

$$
\left[\begin{array}{l}
Q_{x} \\
Q_{y} \\
Q_{z} \\
M_{x} \\
M_{y} \\
M_{z}
\end{array}\right]=\iint_{B} p\left[\begin{array}{l}
n_{1} \\
n_{2} \\
n_{3} \\
n_{4} \\
n_{5} \\
n_{6}
\end{array}\right] d s-\omega_{e}^{2}[\mathrm{M}]\left[\begin{array}{l}
\eta_{1} \\
\eta_{2} \\
\eta_{3} \\
\eta_{4} \\
\eta_{5} \\
\eta_{6}
\end{array}\right]
$$

The definitions of the wave-induced forces and moments acting on the cross deck of a trimaran ship are shown in Figure 4. These forces and moments include Longitudinal in-plane Force $\left(Q_{X}\right)$, Transverse Vertical shear Forces $\left(Q_{Y}\right)$, Transverse in-plane Horizontal Force or Side Force $\left(Q_{Z}\right)$, Transverse Vertical bending moments or roll moment $\left(M_{X}\right)$, Horizontal inplane moments or yaw moment $\left(M_{Y}\right)$ and Transverse torsional moment or pitch moment $\left(M_{Z}\right) . M_{X}, M_{Z}$ and $Q_{Y}$ are very important in cross structure analysis.

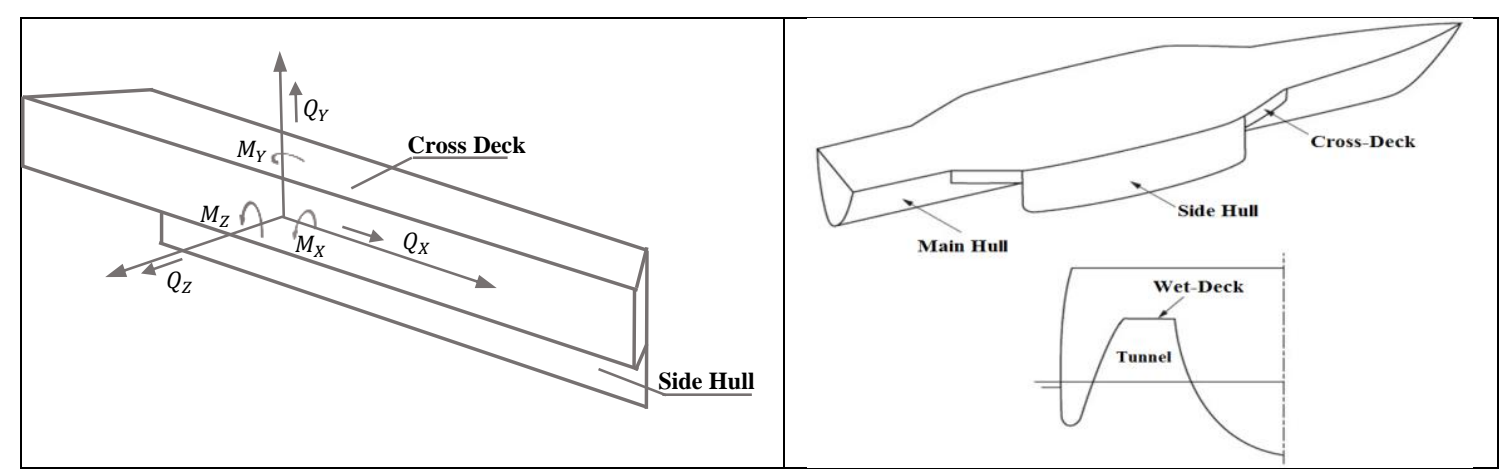

(a)

(b)

Fig. 4 The trimaran ship concept and representation of the wave-induced loads acting on cross deck a) Cross structure b) The main components of trimaran

\subsection{Short-term forecast}

The short-term sea state is considered to be a stationary process or Gaussian process, so in the linear theory the short-term ship response corresponds to a steady (random) sea state can be considered as stationary and ergodic Gaussian narrow banded stochastic process with zero mean. Therefore Within one sea state the amplitudes of the wave induced load and motion effects follow a Rayleigh distribution. In a short-term sea state ship motions and wave-induced load effects depend on many different parameters, such as loading condition, vessel speed, significant wave height, average zero-crossing period, relative wave heading and wave spreading.

It is assumed that the sea surface is constituted by short-crested waves. The directional spectrum $S_{\zeta}(\omega, \theta)$ can be presented as [20]:

$$
S_{\zeta}(\omega, \theta)=S_{\zeta}(\omega) D(\omega, \theta)
$$


where, $S_{\zeta}(\omega)$ is the frequency spectrum and $D(\omega, \theta)$ is directional spreading function. The directional spreading function satisfies the following equation:

$$
\int_{-\pi}^{\pi} D(\omega, \theta) d \theta=1
$$

Usually it is considered that frequency distribution of wave energy is independent of directional distribution. Therefore directional spectrum can be expressed as the following equation:

$$
S_{\zeta}(\omega, \theta)=S_{\zeta}(\omega) D(\theta)
$$

The widely accepted cosine square law for the directional spreading function that proposed by ITTC (International Towing Tank Conference) is adopted in this study:

$$
\left\{\begin{array}{cc}
D_{\text {ITTC }}(\theta)=2 / \pi \cos ^{2} \theta & -\pi / 2 \leq \theta \leq \pi / 2 \\
D(\theta)=0.0 & \text { elsewhere }
\end{array}\right.
$$

Each individual sea state is characterized by a significant wave height, $\mathrm{H}_{\mathrm{s}}$, and a mean zero crossing period, $\mathrm{T}_{\mathrm{z}}$. The wave energy is traveling in a specific direction, commonly considered the same direction as the wind. In this respect, the wave spectrum may be considered as a uni-directional spectrum or the long-crested spectrum, denoted by $\mathrm{S}_{\zeta}\left(\omega, \mathrm{H}_{\mathrm{s}}, \mathrm{T}_{\mathrm{z}},\right)$. In reality, however, for wind-generated waves the wave energy usually spreads over various directions, though the major part of the energy may propagate in the prevailing wind direction (See figure 5). The wave spectrum representing energy in a specific direction is called the directional spectrum or the short-crested spectrum, denoted by $S_{\zeta}\left(\omega, H_{s}, T_{z}, \beta\right)$ in which $\beta$ is the angle between wave component direction and ship direction. $H(\omega, U, \beta+\theta)$ defines the amplitude of response due to unit wave excitation, where $\theta$ is the wave spreading angle, i.e., $\theta$ is the angle between the wave component under consideration and the prevailing wind direction. If the transfer function at various encounter frequencies are designated as $H(\omega, U, \beta+\theta)$, the response spectra of the vessel in $3 D$ irregular waves is $S_{R}\left(\omega, H_{s}, T_{z}, U, \beta\right)[21,22]$.

$$
S_{R}\left(\omega, H_{s}, T_{z}, U, \beta\right)=\int_{-\pi / 2}^{\pi / 2}|H(\omega, U, \beta+\theta)|^{2} S_{\zeta}\left(\omega, H_{s}, T_{z}, \beta+\theta\right) d \theta
$$

It should be noted that for amplitude of the single response component to the single wave component the following relation is used:

$$
R\left(\omega, H_{s}, T_{z}, U, \beta+\theta\right)=|H(\omega, U, \beta+\theta)| \zeta\left(\omega, H_{s}, T_{z}, \beta+\theta\right)
$$




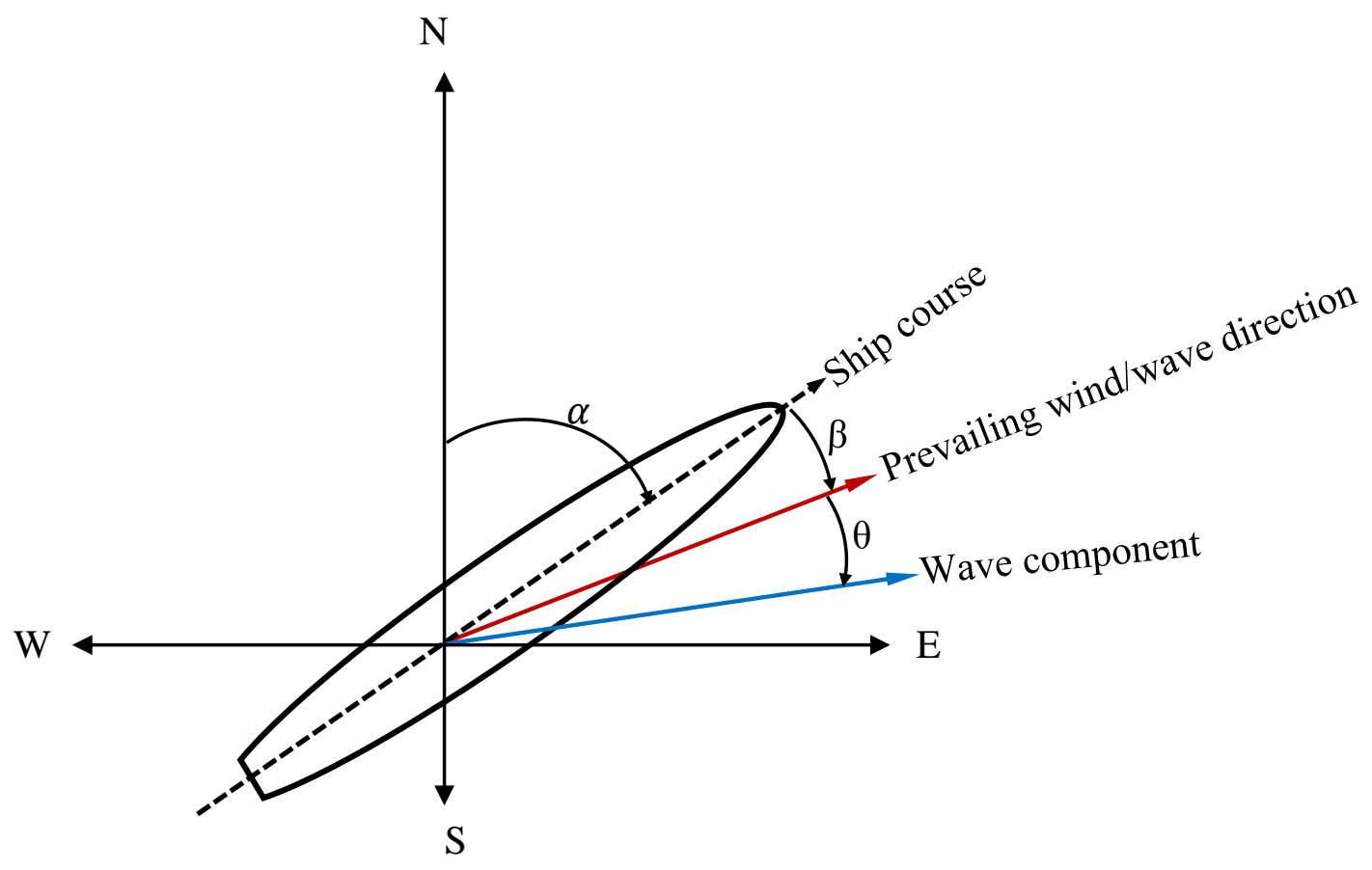

Fig. 5 Notation of relevant angles for short-crested waves.

On the assumption of Gaussian zero mean stationary stochastic process, the variance is the basic statistical parameter as it uniquely determines the short-term statistical behavior of the process. In the case of wave induced load and motion the variance (zero-th order moment) is therefore calculated on the basis of the corresponding transfer function:

For response spectrum:

$$
\begin{gathered}
m_{0}\left(H_{s}, T_{z}, U, \beta\right)=\int_{0}^{\infty} S_{R}\left(\omega, H_{s}, T_{z}, U, \beta\right) d \omega \\
=\int_{-\pi / 2}^{\pi / 2} \int_{0}^{\infty}|H(\omega, U, \beta+\theta)|^{2} S_{\zeta}\left(\omega, H_{s}, T_{z}, \beta+\theta\right) d \omega d \theta
\end{gathered}
$$

The standard deviation (RMS) of short-term responses of motions or loads is defined as follows:

$$
x_{s}=\sqrt{m_{0}\left(H_{s}, T_{z}, U, \beta\right)}
$$

Because the short-term ship response can be considered as a stationary and ergodic Gaussian narrow banded process, the crests and troughs of the response are described by a Rayleigh distribution. The probability of exceeding a given level $x$ of response amplitude, for $\mathrm{i}$-th sea state, $\mathrm{j}$-th wave heading and $\mathrm{k}$-th speed, is calculated by: 


$$
P_{i j k}=\exp \left\{-x^{2} / E\left[\left(H_{s}, T_{z}\right)_{i}, \beta_{j}, U_{k}\right]\right\}
$$

where, $E\left[\left(H_{1 / 3}, T_{z}\right)_{i}, \beta_{j}, U_{k}\right]$ denotes twice of the variance, and can be obtained by the formula:

$$
E\left[\left(H_{s}, T_{z}\right)_{i}, \beta_{j}, U_{k}\right]=2 m_{0}\left(H_{s}, T_{z}, U, \beta\right)
$$

\subsection{Experimental validation of numerical results}

To validate the implementation of MAESTRO's short-term statistics the model tests were conducted in the National Iranian Marine Laboratory (NIMALA) towing tank facilities. This towing tank was established in 2013 with the aim of carrying out various types of design and engineering tests for surface ships and submarines. It is the most efficient and largest country reference at the moment. In 2017 NIMALA joined the Towing Tank Conference (ITTC). It has $400 \mathrm{~m}$ length, $6 \mathrm{~m}$ width and $4 \mathrm{~m}$ depth. The carriage has dimensions of $7 * 7.6$ meters. The speed of the carriage in its slow mode is 0.5 to $5 \mathrm{~m} / \mathrm{s}$ and its top speed is 4.5 to 19 $\mathrm{m} / \mathrm{s}$. The wave maker installed at the NIMALA has the ability to produce regular and irregular waves up to a maximum height of 50 centimeters.

AMTI's MC3A is specifically designed for the precise measurement of forces and moments. The sensor measures the three orthogonal force and moment components along the $\mathrm{X}, \mathrm{Y}$, and $\mathrm{Z}$ axes, producing a total of six outputs. The characteristics of this strain gage sensor make it ideal for research and testing environments. The sensor has a full-scale force capacity of 100 pounds in $\mathrm{Z}$ axes and 50 pounds in $\mathrm{X}$ and $\mathrm{Y}$ axes, and a full-scale moment capacity of $50 \mathrm{lb}$-in about $\mathrm{Z}$ axes and $100 \mathrm{lb}$-in about $\mathrm{X}$ and $\mathrm{Y}$ axes. The AMTI Gen 5 is a signal conditioner and amplifier for use with MC3A force/torque sensor. The Gen 5 is a six channel signal conditioning device where each channel corresponds to one of these six components. For each channel the Gen 5 supplies an excitation voltage to a set of strain gage bridges embedded in the force platform. The resulting output is a low level voltage proportional to that component of the applied mechanical load. This output is amplified, filtered, and then periodically sampled by the Gen 5. Figure 6 shows the AMTI load cell and its amplifier.
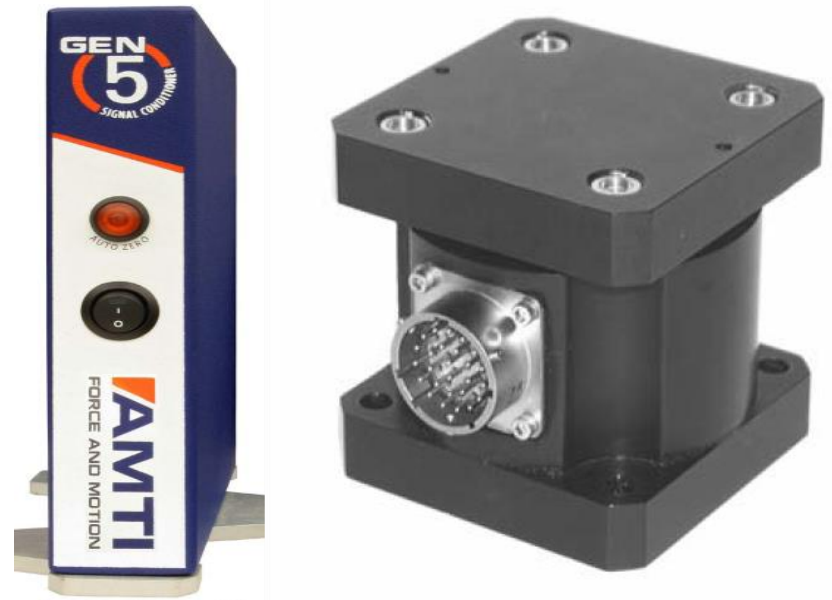

Fig. 6 AMTI load cell and amplifier. 
The model tests were conducted in a regular head wave conditions. Sea keeping model tests were carried out according to the ITTC recommended procedure 7.5-02-07-02.6 (2011). The calibration of load cell was performed according to the ITTC recommended procedure 7.6-02-09 (2002). Seven regular waves with wave lengths from $0.6 \mathrm{~m}$ to $2.4 \mathrm{~m}$ at $0.3 \mathrm{~m}$ increments were generated as incoming waves. The amplitude of incident waves was $0.035 \mathrm{~m}$ in model scale. The model speeds were 0.58 and $1.16 \mathrm{~m} / \mathrm{s}$ which is equivalent to the prototype speeds 10 and 20 knots (corresponding to Froude numbers of 0.15 and 0.30 ) respectively. The normalized force and moment response on the vertical axis is represented as $\frac{F_{i}}{k_{a}}$ and $\frac{M_{i}}{k_{a}}$ respectively. $k_{a}$ and $k_{b}$ defined as follows:

$$
\begin{aligned}
& k_{a}=\rho g L B \zeta_{a} \\
& k_{b}=\rho g L^{2} B \zeta_{a}
\end{aligned}
$$

where $\zeta_{a}$ is the wave amplitude. The horizontal axes represent the normalized wave frequency form as $\omega \sqrt{\frac{L}{g}}$.

The comparison between the MAESTRO and model test results is depicted in Figures 710. The comparison showed that this method had an acceptable accuracy for predicting the RAOs of wave-induced loads of the ship.

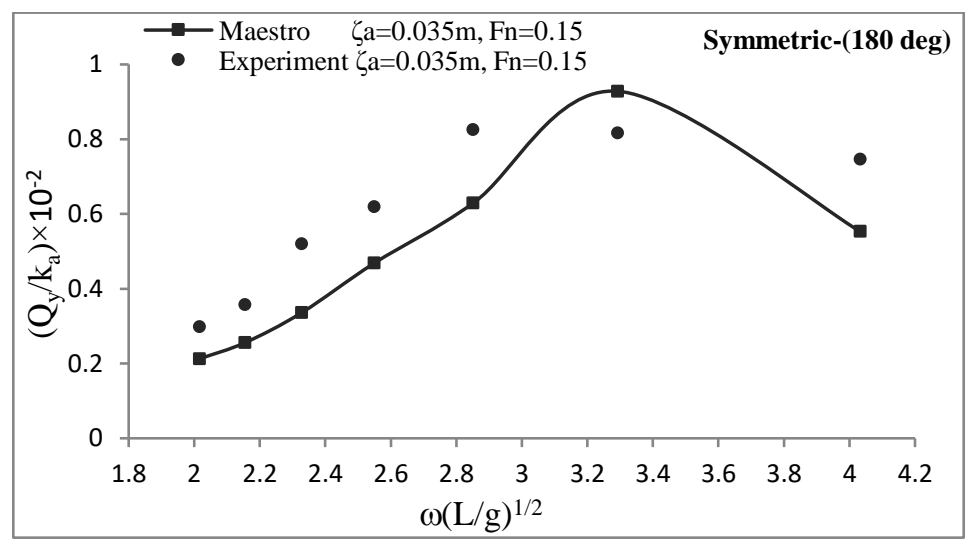

Fig. 7 The comparison between MAESTRO and model test wave-induced vertical shear force at Fn=0.15.

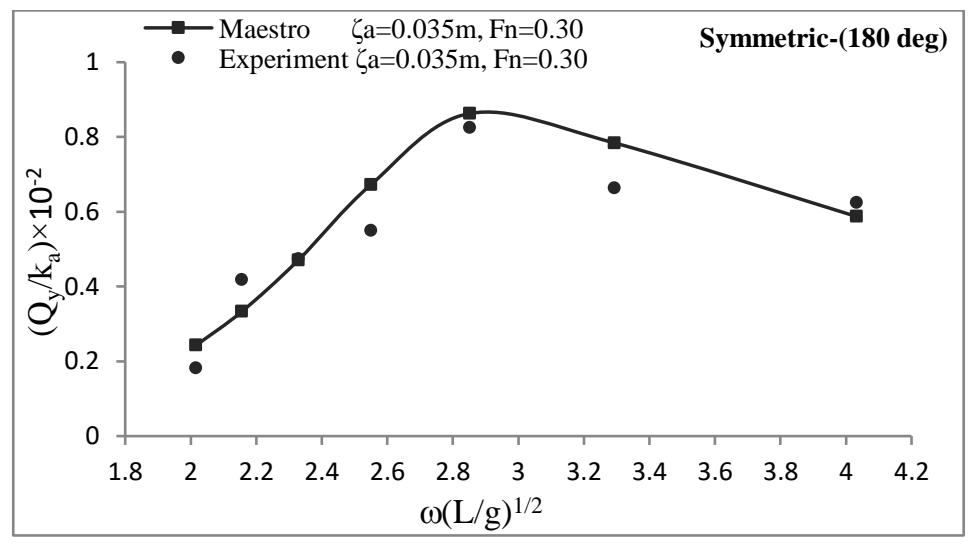

Fig. 8 The comparison between MAESTRO and model test wave-induced vertical shear force at Fn=0.30. 

and Load Responses of a Wave-Piercing Trimaran

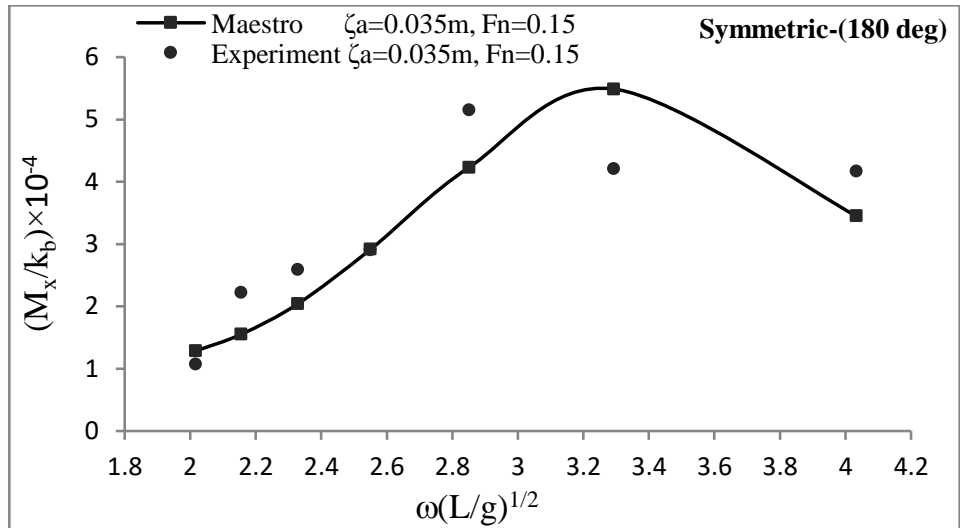

Fig. 9 The comparison between MAESTRO and model test wave-induced vertical bending moment at $\mathrm{Fn}=0.15$.

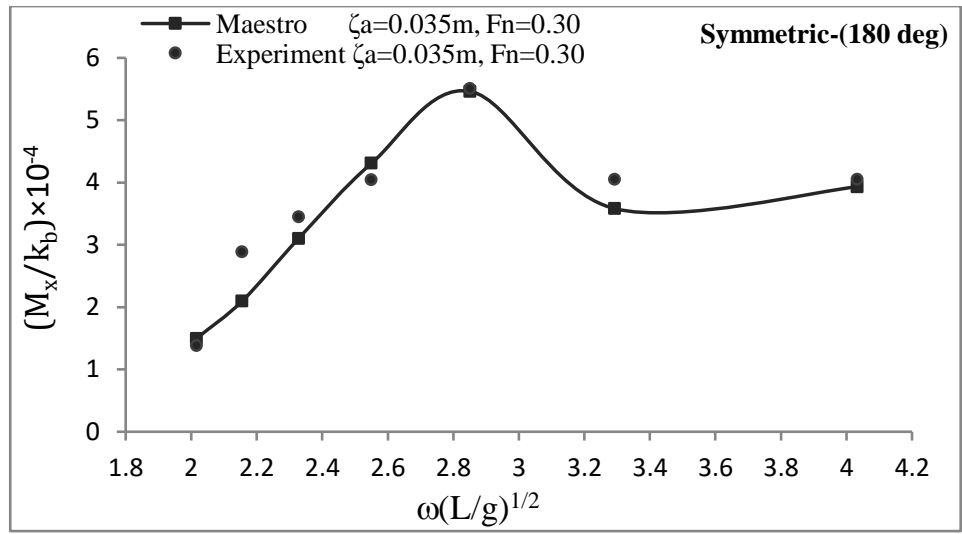

Fig. 10 The comparison between MAESTRO and model test wave-induced vertical bending moment at $\mathrm{Fn}=0.30$.

\section{Results and discussions}

In this study, the short-term statistics of trimaran's wave motions and loads at the service speed of 30 knots. This was carried out for different encounter wave angles from head waves $\left(\beta=180^{\circ}\right)$ to following waves $\left(\beta=0^{\circ}\right)$ at $15^{\circ}$ increments (Figure 11).

In order to find the standard deviation (RMS) of short-term responses for wave loads and motions the two-parameter Bretschneider spectrum is used to model the open sea wave conditions. The wave spectrum is given by [23]:

$$
\begin{array}{r}
S_{\zeta}(\omega)=\frac{5 \omega_{p}^{4} H_{s}^{2}}{16 \omega^{5}} \exp \left[-1.25\left(\frac{\omega_{p}}{\omega}\right)^{4}\right] \\
\omega_{p}=\frac{2 \pi}{T_{p}} \quad T_{p}=1.408 T_{z}
\end{array}
$$

The plotted spectra are presented in Figure 12. The predictions were performed for the sea state duration of 3 hours with $H_{s}, T_{z}(2.0 \mathrm{~m}, 6.5 \mathrm{~s})$ and $(12.5 \mathrm{~m}, 10.5 \mathrm{~s})$. As Figure 12 presents, the most critical effect of the wave energy on the trimaran ship's structure occurs around $\omega_{0}=0.4 \mathrm{rad} / \mathrm{s}$ due to the peak wave energy. 


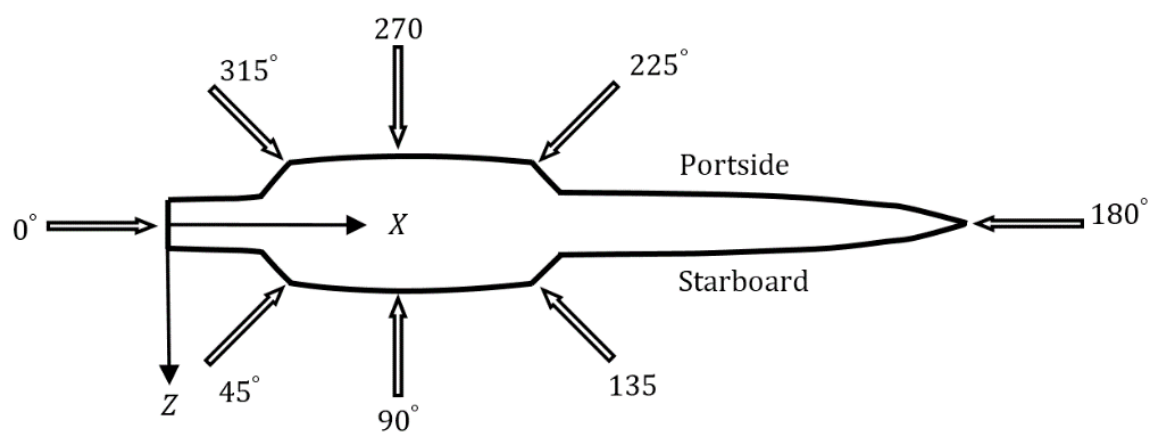

Fig. 11 Heading angle definition.

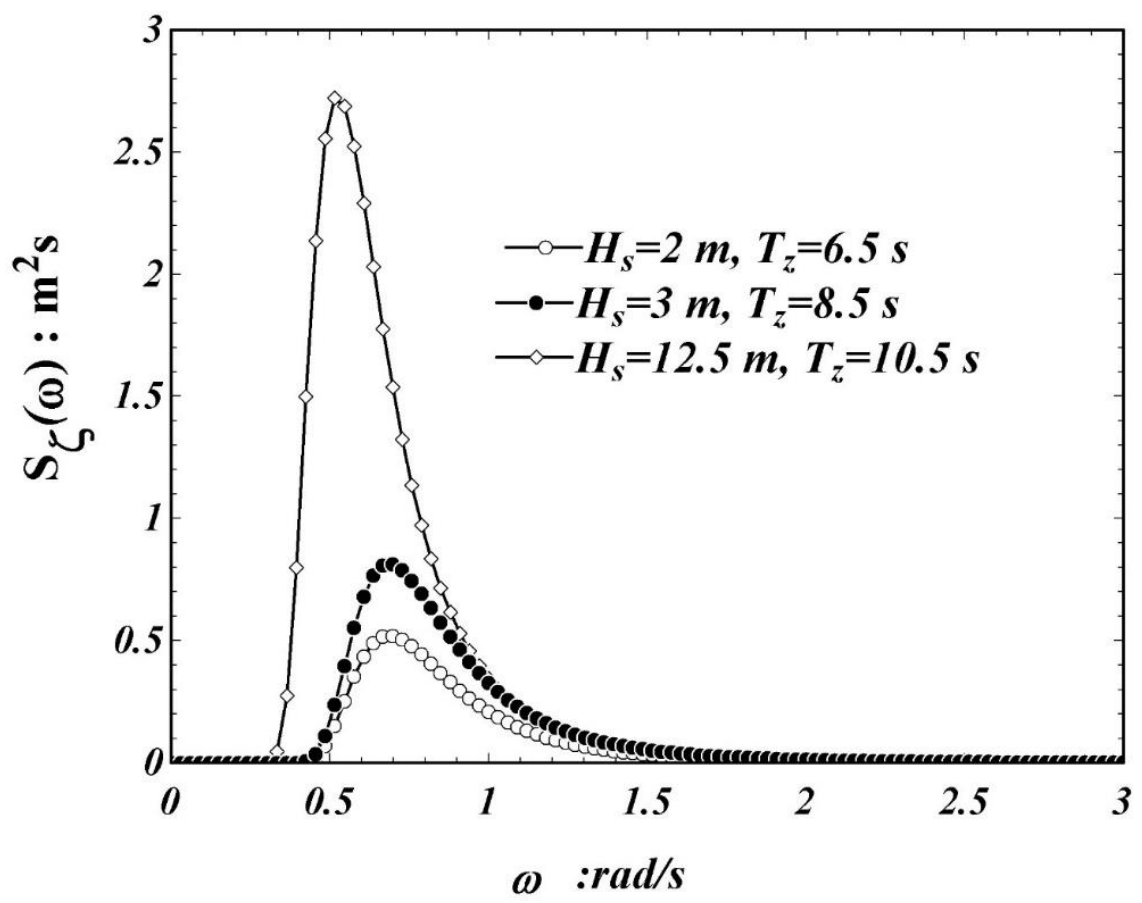

Fig. 12 The plot of Bretschneider wave spectra for different sea states (Using Eq. 19 [23]).

To examine longitudinal wave loads, we chose the mid-ship section to study the vertical bending moment and the $0.25 \mathrm{~L}$ section after a mid-ship to study the vertical shear force. To investigate the cross deck loads, the section joining the cross structure and the main hull was selected. This section is usually the weakest part of the vessel. It is customary to exhibit the results of the short-term statistics in terms of polar diagrams representing the standard deviation of the relevant quantities against the relative wave heading at design speed for each sea condition. The angular coordinates represents wave headings, while the radial coordinates reports wave motions and loads. This helps the designer to have a comprehensive assessment of the ship response and to identify the critical operational conditions in terms of unfavorable headings and combinations of ship speed and wave period quickly. 

and Load Responses of a Wave-Piercing Trimaran

\subsection{Wave-induced motions}

Figure 13 reports the short-term prediction of heave motions in short-crested waves at different headings. As shown in Figure 13, all responses are symmetric with respect to $\left(0^{\circ}-\right.$ $\left.180^{\circ}\right)$ axes because of the features of the trimaran. The magnitudes of the responses rise with an increase in the significant wave height. Because of arrangement of side hull at stern of the trimaran the heave motions appear to be insensitive to change of wave heading from head seas to beam seas. A change in heading angle from beam seas to following seas reduced the heave motions markedly. Higher values of the heave motion curves occur for heading angles $135^{\circ}$ and $225^{\circ}$ and lower magnitude for wave heading $30^{\circ}$ and $330^{\circ}$. It can be observed that, the responses are almost similar in magnitude and physical trends for all three different side hulls.

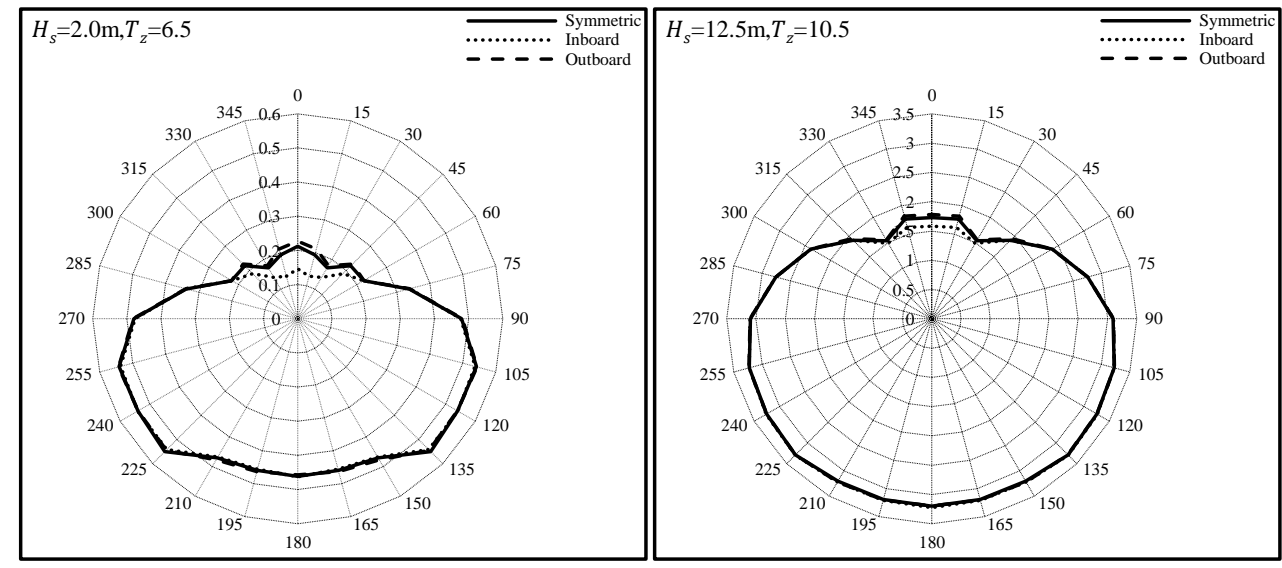

Fig. 13 Polar plots of RMS values of heave motions $(\mathrm{m})$ in different sea states at $\mathrm{Fn}=0.45$.

Figure 14 represents the responses of pitch motions. As shown in Figure 14, responses have port/starboard symmetry and the magnitudes increase as the significant wave height increases. It is obvious that trends and magnitudes of pitch responses are the same for all three side hull configurations. The pitch motion of the vessel in beam seas is minimum compared to wave propagating on other directions as there are no excitation forces to create longitudinal moment of the vessel. The response of pitch is more severe in head sea and following sea. Furthermore, the degree of pitch in head sea is higher than the value in following sea. In summary, due to the same hydrostatic properties and wetted surface of side hulls which offer equal motion damping, wave motion responses are not sensitive to change in side hull configurations.

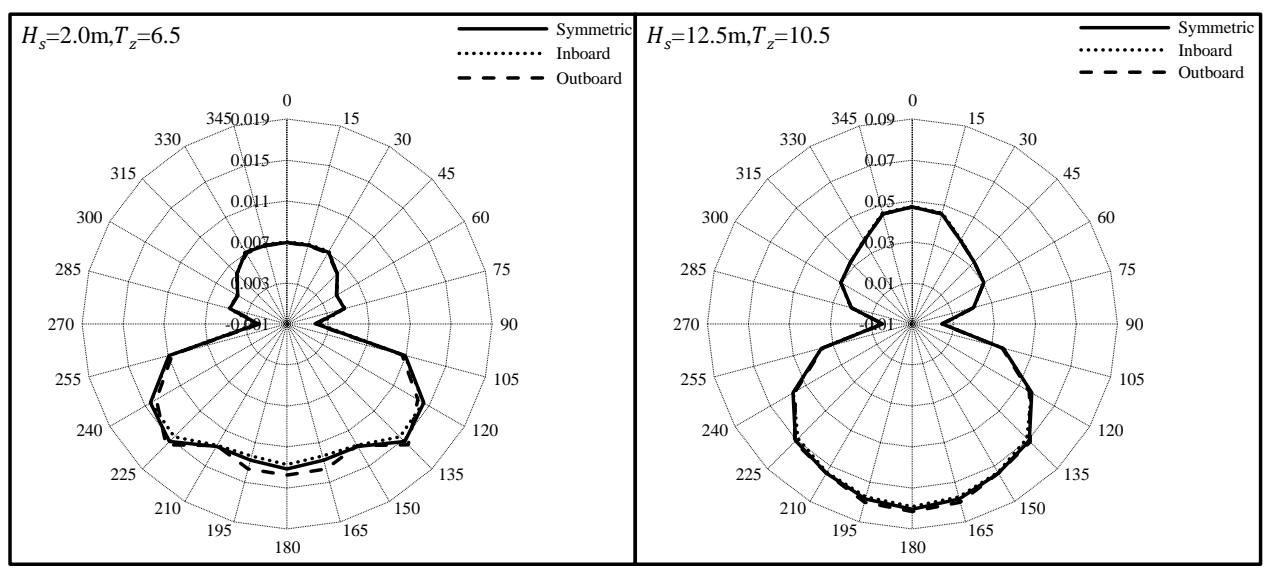

Fig. 14 Polar plots of RMS values of pitch motions (RAD) in different sea states at Fn=0.45. 


\subsection{Longitudinal wave-induced loads}

Figure 15 presents the short-term statistics of vertical bending moments in short-crested waves. The plots of all side hull configurations at their respective wave headings are similar regarding magnitude and physical trends. The changes in the side hull form did not affect the responses in these operational situations. The maximum response values emerged at head seas and rose with the increase of the significant wave height. However, the minimum response values appeared in beam sea condition $\left(90^{\circ}\right.$ and $\left.270^{\circ}\right)$.

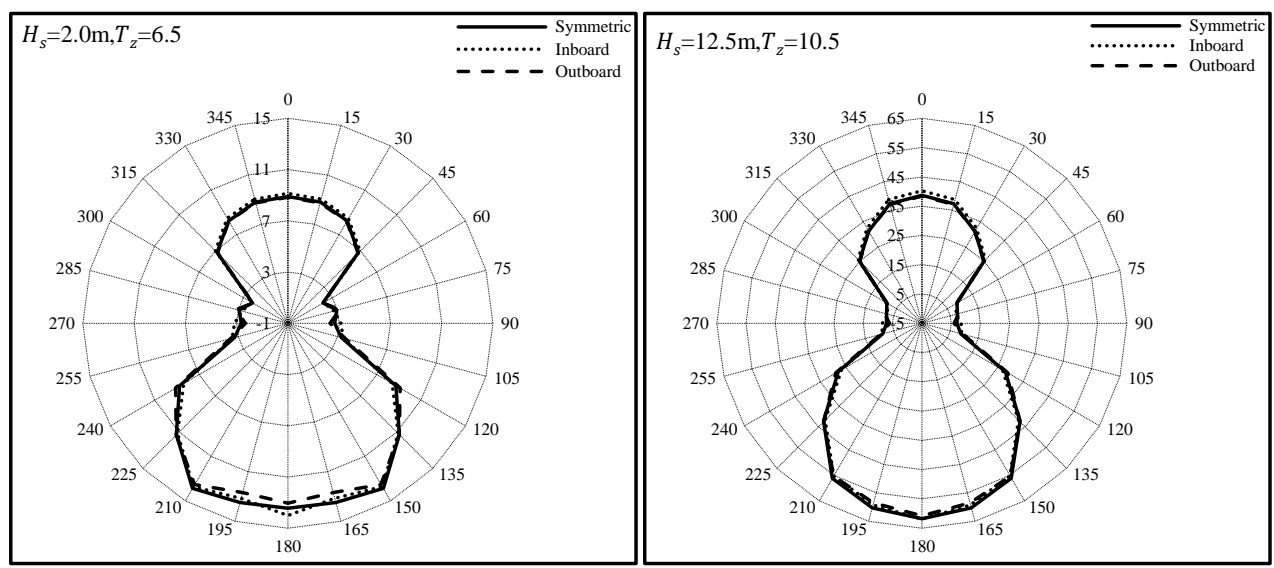

Fig. 15 Polar plots of RMS values of vertical bending moments (MN.m) in different sea states at $\mathrm{Fn}=0.45$.

Figure 16 represents the distribution of short-term prediction of vertical shear forces at $0.25 \mathrm{~L}$ section after a midship. It shows that changes in the transverse shear forces with wave heading had great similarity to that of the vertical bending moment. The plots are similar to the responses regarding magnitude and physical trends except for the head

sea condition. In head seas, the maximum response values of vertical shear forces appeared in inboard and secondly in symmetric configurations. The minimum response

values appeared in outboard side hull configuration. However the difference is not considerable.

In summary, trend of the longitudinal wave loads including vertical bending moment and shear force are closely similar to pitch motion responses. In the beam sea condition this loads is minimum. Excitation force in the beam sea condition cannot induce vertical bending moment and shear force on cross section normal to the longitudinal axis. Because of the arrangement of side hull at stern, the trimaran suffers more severe longitudinal wave loads in head seas than the one in following seas. Longitudinal wave load on main hull of a trimaran was found, as for a monohull. The interaction of the wave buoyancy forces and the weight of the ship cause vertical bending moment and shear force on cross section normal to the longitudinal axis. Displacement of side hulls are less than $6 \%$ of the total displacement [24]. As a result these loads mostly lead to formation of wave induced load on main hull. So for trimaran the effect of the side hull configuration on the longitudinal wave load is small. 

and Load Responses of a Wave-Piercing Trimaran

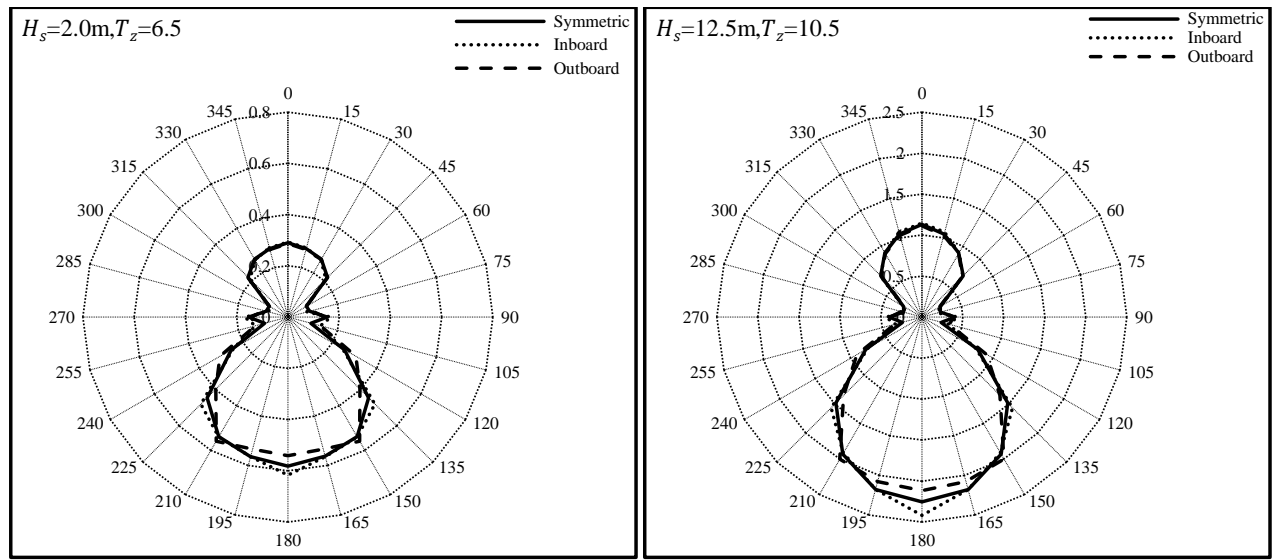

Fig. 16 Polar plots of RMS values of vertical shear forces $(\mathrm{MN})$ in different sea states at Fn=0.45.

\subsection{Transverse wave-induced loads}

Figure 17 presents the short-term statistics of transverse bending moments. As shown in Figure 17 , the responses for stern waves $\left(270^{\circ}\right.$ to $\left.90^{\circ}\right)$ are almost similar in all three different side hulls regarding magnitude and physical trends. In bow waves $\left(90^{\circ}\right.$ to $\left.270^{\circ}\right)$, the response increased significantly and detached from each other due to individual side hull configurations. The maximum response values appear in heading angles $120^{\circ}$ and $240^{\circ}$ for inboard outriggers. In head wave condition, responses decreased significantly and were the same for all three side hull configurations. The inboard and outboard types had the highest and lowest peak magnitudes, respectively. In all wave headings, outboard form performed better than other cases.

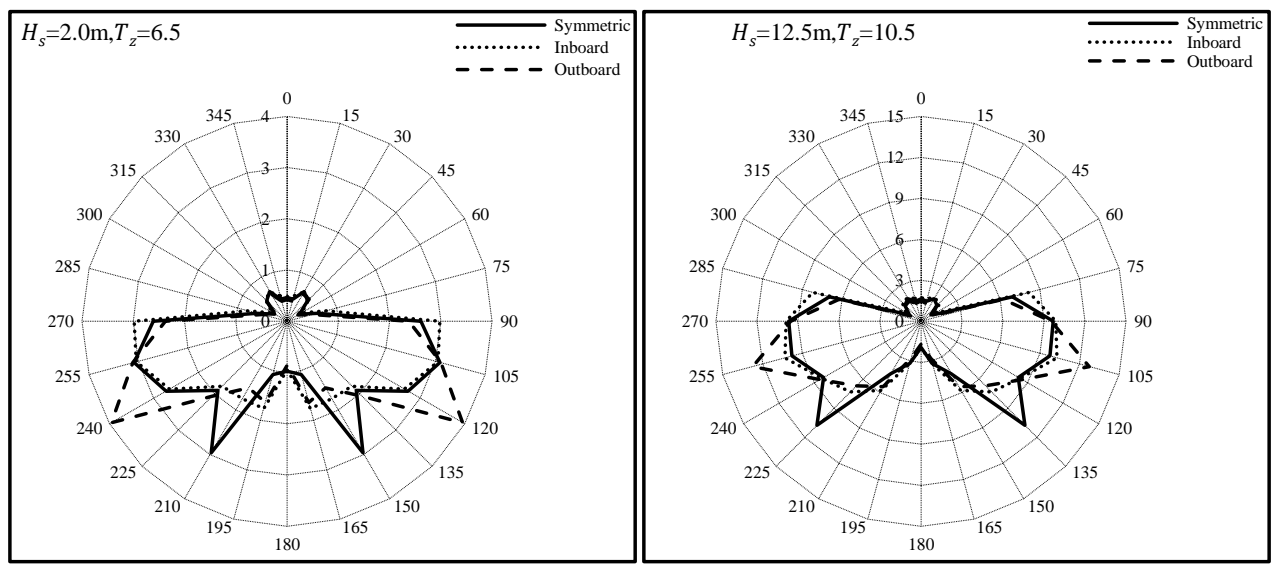

Fig. 17 Polar plots of RMS values of transverse bending moments (MN.m) in different sea states at $\mathrm{Fn}=0.45$.

The results of the short-term predictions of transverse shear forces are depicted in Figure 18. It is observed that for stern waves $\left(270^{\circ}\right.$ to $\left.90^{\circ}\right)$, alterations in the vertical shear forces are, overall, similar to those of vertical bending moment. As shown in Figure 18, the responses are almost similar in physical trends for all three different side hulls. The maximum response values are at head seas, which rise with an increase in the significant wave height. There is a clear distinction between the response peak magnitudes and the inboard model which shows the highest response. It can be observed that the outboard model performs better than the other ones. 


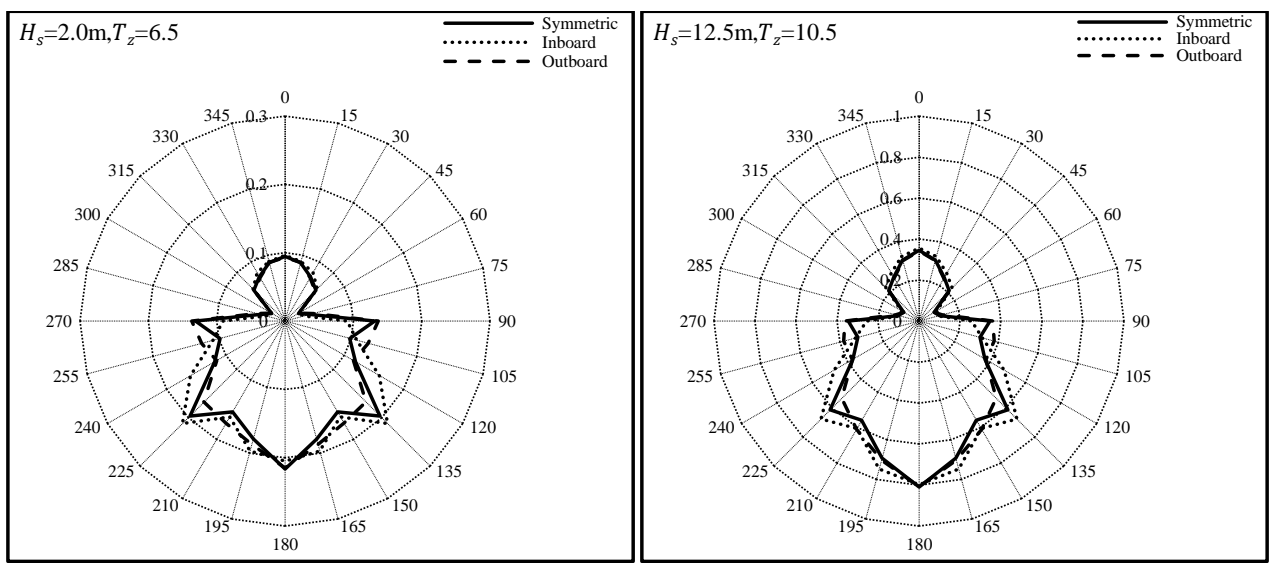

Fig. 18 Polar plots of RMS values of transverse shear forces $(\mathrm{MN})$ in different sea states at Fn=0.45.

Figure 19 presents the short-term statistical analysis of transverse torsion moments. The distinctive feature of this Figure is the high peak magnitude for inboard model in wave headings $\left(90^{\circ}\right.$ to $\left.270^{\circ}\right)$. The outboard and symmetric forms are similar regarding physical trends and the peak magnitudes are approximately the same. The maximum transverse torsion moments appear in head sea condition in three kinds of side-hull forms. As shown in Figure19, in stern wave conditions, the difference between the responses of the three models are not significant. In summary, Transverse wave loads include transverse shear forces, transverse bending moments and transverse torsional moments arise from the interaction between the side hulls and main hull. Furthermore, the fluid force acting on a side hull will transfer to the main hull by cross structure. The two side hulls and main hull will cause interference mutually. Different form of side hulls will bring about different interference. The transverse wave loads of trimaran will decrease when the three hulls take favorable interference. It can be observed that the outboard side hull with less interference compared with other configurations performs better in transverse wave loads conditions. From viewpoint of resistance the outboard side hull also produce the lowest interference drag between these three side hull configurations [24].
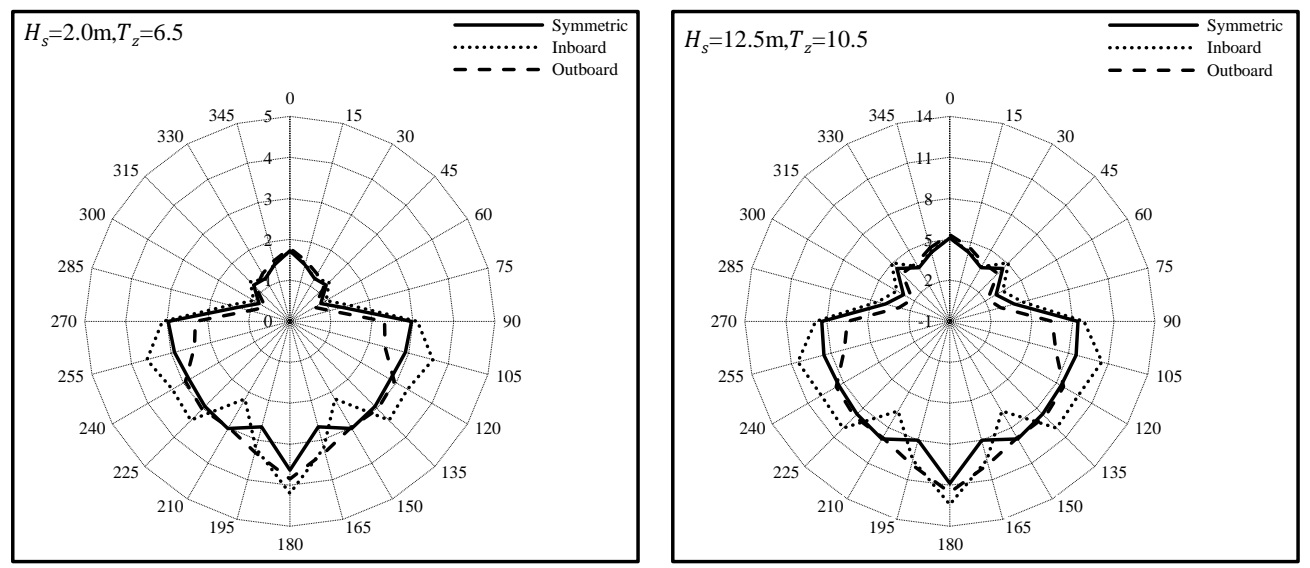

Fig. 19 Polar plots of RMS values of transverse torsion moments (MN.m) in different sea states at $\mathrm{Fn}=0.45$. 


\section{Conclusions}

In this study, wave-induced motions and loads of trimaran ship were investigated by means of short-term statistical analysis with three kinds of side hull configurations (symmetric, inboard, and outboard types). Predictions were made using a 3D-panel method code, MAESTRO-Wave, at various sea states and wave headings. Based on the results of the study, the following conclusions can be drawn:

1- Wave motion responses are not sensitive to changes in side hull configurations for all headings in pitch motion and between $30^{\circ}$ and $330^{\circ}$ wave headings in case of heave motion. In stern wave condition between $330^{\circ}$ and $30^{\circ}$, inboard shape performs better than the other forms in sea state $\mathrm{H}_{\mathrm{s}}, \mathrm{T}_{\mathrm{z}}(2.0 \mathrm{~m}, 6.5 \mathrm{~s})$.

2- In longitudinal wave load conditions, the responses were found to be insensitive to the changes in the side hull shape except for vertical shear forces in head seas for which the outboard model performs slightly better than the other side hulls. In transverse wave load conditions, changes in the side hull form influence the responses. It is also found that the outboard side hull performs better than the other side hull configurations.

3- Both transverse bending moments and transverse shear force responses are significant in head seas but significantly small in beam seas. Transverse bending moments have higher response magnitudes in oblique seas.

4- The comparison between the MAESTRO and model test results showed that the procedure has an acceptable accuracy for predicting the RAOs of wave-induced loads of the ship.

5- The result of these analyses indicate that the outboard side hulls offer slightly better performance in waves in comparison to the other concept but the difference appears not to be very significant.

\section{Acknowledgements}

The authors would like to extend their thanks to Dr Amin Najafi and Mr Habib Alikhanzadeh Firozi of National Iranian Marine Laboratory (NIMALA) for their help in running the tests.

\section{REFERENCES}

[1] Brizzolara, S. and Rizzuto, E. (2001) 'Global Wave Loads for a Trimaran Ship', Proceedings of International Conference on Fast Sea Transportation and Research, Southampton, USA.

[2] Boote, D. Colaianni, T. and Rizzo, CM. (2003) 'Structural analysis of a trimaran fast ferry', Proceedings of the 7th Conference on Fast Sea Transportation, Ischia, Italy.

[3] Boote, D. Colaianni, T. and Rizzo, CM. (2003) 'Strength assessment of trimaran fast ferries', Proceedings of the 14th International Conference of Ship and Shipping Research, Palermo, Italy, pp.1-9.

[4] Fang, CC. Lee, YH. Chan, HS. and Wu, HT. (2008) 'Numerical investigation on wave load characteristics of a high speed trimaran in oblique waves', Journal of Taiwan Society of Naval Architects and Marine Engineers, vol.27, pp.71-79.

[5] Fang, MC. and Chen, TY. (2008) 'A parametric study of wave loads on trimaran ships traveling in waves', Journal of Ocean Engineering, vol.35, pp.749-762. https://doi.org/10.1016/j.oceaneng.2008.02.001

[6] Min, X. and Shi-Lian, Z. (2011) 'A numerical study on side hull optimization for trimaran', Journal of Hydrodynamics vol.3, pp.265-272. https://doi.org/10.1016/S1001-6058(10)60112-6

[7] Hashimoto, H. Amano, S. Umeda, N. and Matsuda, A. (2011) 'Influence of Side-Hull Positions on Dynamic Behaviors of a Trimaran Running in Following and Stern Quartering Seas', Proceedings of 21st International Conference of Offshore and Polar Engineering, Maui, Hawaii, USA, pp.573-580. 
[8] Shehzad, K. Ren, HL. Zhen, CB. And Khurram, A. (2012) 'Global Strength Assessment of Trimaran Structure', Journal of Advanced Materials Research, vol.538, pp. 2860-2863. https://doi.org/10.4028/www.scientific.net/AMR.538-541.2860

[9] Bashir, MB. Tao, L. Atlar, M. and Dow, RS. (2013) 'Experimental and numerical investigation of the wave-induced loads on a Deep-V catamaran in regular waves ', Proceedings of the 32nd International Conference on Ocean, Offshore and Arctic Engineering ,Nantes ,France. https://doi.org/10.1115/OMAE2013-10212

[10] Ma, M. Zhao, C. and Hughes, O. (2014) 'A practical method to apply hull girder sectional loads to fullship 3D finite-element models using quadratic programming', Journal of Ships and Offshore Structures. 9:257-265. https://doi.org/10.1080/17445302.2013.770725

[11] Prini, F. Benson, S. Birmingham, RW. Sheppard, PJ. Phillips, HJ. And Mediavilla-Varas, J. (2015) 'Seakeeping Analysis of a High-Speed Search and Rescue Craft by Linear Potential Theory', Proceedings of International Conference on Lightweight Design of Marine Structures, Glasgow, UK.

[12] Xiaobo, W. Ren, H. Sun, Y. Wang, D. and Wang, ZY. (2016) 'Experimental Investigation of Wave Loads Based on Trimaran Self-Propulsion Model', Proceedings of 35th International Conference on Ocean, Offshore and Arctic Engineering, Busan, South Korea. https://doi.org/10.1115/OMAE2016-54550

[13] Kim, MS. Jung, KH. Park, SB. (2018) 'Wave induced coupled motions and structural loads between two offshore floating structures in waves', Brodogradnja, 69(3), 149-173. https://doi.org/10.21278/brod69309

[14] Tang, H. Ren, H. Zhong, Q. (2019) 'Design and Model Test of Structure Monitoring and Assessment System for Trimaran', Brodogradnja, 70(2), 111-134. https://doi.org/10.21278/brod70206

[15] Jiang, Z. Gao, Y. Liu, J. (2019) 'A lid approach for predicting wave induced motions of trimaran in regular waves', Brodogradnja, 70(2), 171-185. https://doi.org/10.21278/brod70209

[16] MAESTRO Version 10.0 Users' Manual. Stevensville (MD): Advanced Marine Technology Centre. Available from: http://www.MAESTROmarine.com

[17] Mohammadi, M. Khedmati, MR. Akbari Vakilabadi, K. (2013) 'Effects of hull damage on global loads acting on a trimaran ship', Ships and Offshore Structures 10:635-652.

https://doi.org/10.1080/17445302.2014.943387

[18] Salvesen, N. Tuck, EO. and Faltinsen, O. (1970) 'Ship Motions and Sea Loads', Trans . SNAME, vol. 78, pp. 250-269.

[19] Newman, J.N (1977) "Marine Hydrodynamics, The MIT Press, Cambridge, Mass. https://doi.org/10.7551/mitpress/4443.001.0001

[20] Guo, Q. Xu, Z. and Sun, Y. (2011) 'Three-dimensional ocean wave simulation based on directional spectrum', Journal of Applied Mechanics and Materials, vol. 94-96, pp. 2074-2079. https://doi.org/10.4028/www.scientific.net/AMM.94-96.2074

[21] Mansour AE. (2012) 'Long-Term Properties and Combinations of Stochastic Hull Girder Loads on Ships. PhD dessert', University of California, Berkeley.

[22] Jiao, J. Sun, S. and Ren, H. (2016). 'Predictions of wave induced ship motions and load by large scaled of model measurement at sea and numerical analysis', Brodogradnja, 67(2), 81-100. https://doi.org/10.21278/brod67206

[23] Sandvik, CM. (2012) 'Wave-to-Wire Model of the Wave Energy Converter Bolt2', Norwegian University of Science and Technology.

[24] Ackers, B. Michael, TJ. Tredennik, OW. Landen, HC. et al. (1997) 'An investigation of the resistance characteristics of powered trimaran side hull configurations’, SNAME Transactions 105:349-373.

\footnotetext{
Submitted: $\quad$ 01.07.2018. Abolfath Abolfath Askarian Khoob ${ }^{1}$

Email: A.Askariankhoob@aut.ac.ir

Accepted: 25.06.2020. Mohammad Javad Ketabdari ${ }^{1^{*}}$

${ }^{1}$ Department of Maritime Engineering, Amirkabir University of

Technology, Hafez Ave, No. 424, P.O. Box 15875-4413,Tehran, Iran.

* Corresponding author Email: ketabdar@aut.ac.ir
} 